ISSN: 2052-5206

journals.iucr.org/b

\title{
Chemical and structural variability in cubic spinel oxides
}

\section{Ferdinando Bosi}

Acta Cryst. (2019). B75, 279-285

\section{IUCr Journals CRYSTALLOGRAPHY JOURNALS ONLINE}

Copyright (C) International Union of Crystallography

Author(s) of this article may load this reprint on their own web site or institutional repository provided that this cover page is retained. Republication of this article or its storage in electronic databases other than as specified above is not permitted without prior permission in writing from the IUCr.

For further information see http://journals.iucr.org/services/authorrights.html 
STRUCTURAL SCIENCE CRYSTAL ENGINEERING MATERIALS

ISSN 2052-5206

Received 14 December 2018

Accepted 12 February 2019

Edited by P. Bordet, Institut Néel, France

Keywords: cubic spinel oxides; distortion; ionic potential; crystal chemistry.

Supporting information: this article has supporting information at journals.iucr.org/b

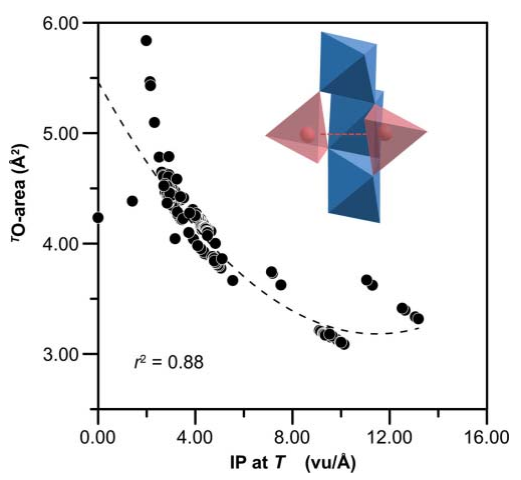

C 2019 International Union of Crystallography

\section{Chemical and structural variability in cubic spinel oxides}

\author{
Ferdinando Bosi*
}

Dipartimento di Scienze della Terra, Sapienza Università di Roma, Piazzale Aldo Moro 5, Rome RM 00185, Italy. *Correspondence e-mail: ferdinando.bosi@uniroma1.it

The empirical relations between cubic spinel oxides of different compositions were investigated using data from 349 refined crystal structures. The results show that the spinel structure is able to tolerate many constituents (at least 36) by enlarging and decreasing the tetrahedra and octahedra. This is reflected in a large variation in tetrahedral and octahedral bond distances. The oxygen positional parameter $(u)$ may be regarded as a measure of the distortion of the spinel structure from cubic close packing or of the angular distortion of the octahedron. The distortion can best be explained in terms of ionic potential (IP), which merges the size and charge properties of an ion. Sterically induced distortion depends on ion size, whereas electrostatically induced distortion is caused by cation-cation repulsion across faces of tetrahedra and shared edges of octahedra. The strong correlations between the $u$ parameter and the IP at the $T$ and $M$ sites are consistent with the main role played by the both charge and size. Large distortions $(u \gg 0.27)$ result in oxygen-oxygen distances of the octahedron shorter than $2.50 \AA$, which would lead to structural instability because of increased non-bonded repulsion forces between the oxygen atoms.

\section{Introduction}

Spinel-type compounds have a central role both in the Earth sciences and in materials sciences. Minerals with the spinel structure are found in a wide range of geological environments, from upper mantle to crust, and occur in extraterrestrial geological environments, e.g. the Moon, Mars and meteorites. Moreover, ceramic materials with the spinel structure show a huge range of mechanic, optic, thermoelectric and magnetic properties and, as a result, they are suitable for many applications.

Oxide spinels have the general chemical formula $A B_{2} \mathrm{O}_{4}$, where $A$ and $B$ are constituents (not crystallographic sites) with charges ranging from 0 to +6 that yield root-charge arrangements such as $A^{0} B_{2}^{4+} \mathrm{O}_{4}, A^{2+} B_{2}^{3+} \mathrm{O}_{4}, A^{6+} B_{2}^{+} \mathrm{O}_{4}$ and $A^{4+} B_{2}^{2+} \mathrm{O}_{4}$ corresponding to compositions such as those of $\mathrm{Mn}_{2} \mathrm{O}_{4}, \mathrm{MgCr}_{2} \mathrm{O}_{4}, \mathrm{MoNa}_{2} \mathrm{O}_{4}$ and $\mathrm{SiMg}_{2} \mathrm{O}_{4}$, respectively (Greedan et al., 1998; Lenaz et al., 2004; Kudoh et al., 2007; Fortes, 2015). The spinel structure is a cubic close-packed (c.c.p.) array of anions with $A$ and $B$ constituents occupying one-eighth of the tetrahedrally $(T)$ and one-half of the octahedrally $(M)$ coordinated sites. In the space group $F d \overline{3} m$, the unit-cell parameter $a$ and oxygen fractional coordinate $u$ define the resulting tetrahedral $(T-\mathrm{O})$ and octahedral $(M-$ $\mathrm{O})$ bond lengths as well as other geometrical parameters of the structure such as polyhedron volumes, interatomic distances and bond angles (e.g. Sickafus et al., 1999).

Spinels are traditionally denoted as either 'normal' or 'inverse': the $M$ site of the former is occupied by ions with the 
same formal charge, whereas the $M$ site of the latter is occupied by ions with different formal charges. As an example, the distribution of $A$ and $B$ cations over $T$ and $M$ may lead to two different site populations in the 2-3 spinels: (1) in normal spinels, the $A^{2+}$ cation occupies $T$ and the two $B^{3+}$ cations occupy $M$ (e.g. $\mathrm{MgAl}_{2} \mathrm{O}_{4}$, spinel); (2) in inverse spinels, one of the $B^{3+}$ cations occupies $T$ and the remaining $A^{2+}$ and $B^{3+}$ cations occupy $M$ (e.g. $\mathrm{FeFe}_{2} \mathrm{O}_{4}$, magnetite). Similar site populations occur in the 4-2 spinels: (1) in normal spinels, the $A^{4+}$ cation occupies the $T$ site and two $B^{2+}$ cations occupy the $M$ site (e.g. $\gamma$ - $\mathrm{SiMg}_{2} \mathrm{O}_{4}$, ringwoodite); (2) in inverse spinels, the $B^{2+}$ cation occupies $T$, and the remaining $A^{4+}$ and $B^{2+}$ cations occupy $M$ (e.g. $\mathrm{TiFe}_{2} \mathrm{O}_{4}$, ulvöspinel). In general, given the structural formula ${ }^{T}\left(A_{1-i} B_{i}\right)^{M}\left(A_{i} B_{2-i}\right) \mathrm{O}_{4}$, the two extreme distributions correspond to $i=0$ (normal) and $i=1$ (inverse), where $i$ is the inversion parameter and represents the degree of disorder in the cation distribution; for a random cation distribution $i=\frac{2}{3}$.

The $u$ parameter is of particular importance in the spinel crystal structure, and is the only free atomic coordinate in the ideal spinel structure for anions located at Wyckoff positions at $32 e(u, u, u)$, while constituents at the $T$ and $M$ sites are fixed at $8 a\left(\frac{1}{8}, \frac{1}{8}, \frac{1}{8}\right)$ and $16 d\left(\frac{1}{2}, \frac{1}{2}, \frac{1}{2}\right)$, respectively. Note, the octahedron $\mathrm{MO}_{6}$ is not regular but trigonally distorted (point symmetry $\overline{3} m$ ) with six equivalent bond distances and bond angles $\neq 90^{\circ}$, whereas the tetrahedron $T_{4}$ is always regular (point symmetry $\overline{4} 3 \mathrm{~m}$ ). The deviation of anions from ideal c.c.p. positions has implications not only for crystallographic properties (all geometrical parameters vary) but also for material properties, for instance, the angle $T-\mathrm{O}-M\left(125.3^{\circ}\right.$ in ideal c.c.p.) is the coupling angle for the primary superexchange interaction in ferrimagnetic oxide spinels (e.g. Iida, 1957). Other implications concern the petrogenetic information that may be derived from the $u$ parameter (e.g. Princivalle et al., 1999; Lenaz et al., 2009, 2015; Lucchesi et al., 2010). Moreover, $u$ also correlates with the physical properties of spinel such as bulk modulus (e.g. Kudoh et al., 2007; Nestola et al., 2011).

This paper explores the crystal structures of cubic spinel oxides with different compositions. By using a large data set, empirical relations will be developed in order to show the role of steric and electrostatic interactions in determining the structural and chemical variations in spinel.

\section{Data set}

Chemical and structural data for 349 spinel oxides with space group $F d \overline{3} m$ were taken from the literature: Reuter et al. (1969; $\left.\mathrm{CdV}_{2} \mathrm{O}_{4}\right)$; Furuhashi et al. (1973; $\left.\mathrm{GeCo}_{2} \mathrm{O}_{4}\right)$; Marumo et al. (1977); Von Dreele et al. (1977); Siegel (1978); Finger et al. (1979) (eight sets total); Garcia Casado \& Rasines (1982) (two sets total); Díez Viñuela et al. (1983) (three sets total); Della Giusta et al. (1986, 1996) (16 sets total); O'Neill et al. (1991, 1992, 1994) (37 sets total); Peterson et al. (1991); O'Neill (1992) (11 sets total); Roelofsen et al., 1992 (13 sets total); Hazen et al., 1993 (four sets total); Larsson et al., 1994 (three sets total); Lucchesi \& Della Giusta (1994, 1997) (nine sets total); Waerenborgh et al. (1994a,b) (22 sets total); Millard et
Table 1

Relevant constituents $(=36)$ occurring in spinel oxides.

\begin{tabular}{lllllll}
\hline Charge & & & & & & \\
\hline Zero & 1 & 2 & 3 & 4 & 5 & 6 \\
\hline Vacancy & $\mathrm{Ag}^{+}$ & $\mathrm{Cd}^{2+}$ & $\mathrm{Al}^{3+}$ & $\mathrm{Ge}^{4+}$ & $\mathrm{Sb}^{5+}$ & $\mathrm{Mo}^{6+}$ \\
& $\mathrm{Cu}^{+}$ & $\mathrm{Co}^{2+}$ & $\mathrm{Co}^{3+}$ & $\mathrm{Mn}^{4+}$ & & $\mathrm{W}^{6+}$ \\
& $\mathrm{Li}^{+}$ & $\mathrm{Cu}^{2+}$ & $\mathrm{Cr}^{3+}$ & $\mathrm{Si}^{4+}$ & & \\
& $\mathrm{Na}^{+}$ & $\mathrm{Fe}^{2+}$ & $\mathrm{Fe}^{3+}$ & $\mathrm{Sn}^{4+}$ & & \\
& & $\mathrm{Hg}^{2+}$ & $\mathrm{Ga}^{3+}$ & $\mathrm{Ti}^{4+}$ & & \\
& & $\mathrm{Mg}^{2+}$ & $\mathrm{In}^{3+}$ & $\mathrm{V}^{4+}$ & & \\
& $\mathrm{Mn}^{2+}$ & $\mathrm{Ir}^{3+}$ & & & \\
& & $\mathrm{Ni}^{2+}$ & $\mathrm{Mn}^{3+}$ & & & \\
& $\mathrm{V}^{2+}$ & $\mathrm{Ni}^{3+}$ & & & \\
& $\mathrm{Zn}^{2+}$ & $\mathrm{Rh}^{3+}$ & & & \\
& & & $\mathrm{Sc}^{3+}$ & & \\
\end{tabular}

al. (1995) $\left(\mathrm{TiZn}_{2} \mathrm{O}_{4}\right)$; Carbonin et al. (1996) (three sets total); Lucchesi et al. (1996, 1998a,b, 1999) (50 sets total); Greedan et al. (1998); Andreozzi et al. (2000) (11 sets total); Matsuno et al. (2001); Rohrer (2001) (three sets total, $\mathrm{MgIn}_{2} \mathrm{O}_{4}, \mathrm{SnZn}_{2} \mathrm{O}_{4}$ and $\left.\mathrm{SnCo}_{2} \mathrm{O}_{4}\right)$; Welch et al. (2001); Lavina et al. $(2003 a, b)(20$ sets total); Bosi et al. (2004, 2007, 2009, 2010) (45 sets total); Antao et al. (2005) (45 sets total); Matsushita et al. (2005); Nakatsuka et al. (2006); Weil \& Stöger (2006); Hålenius et al. (2007); Kudoh et al. (2007) (five sets total); Nestola et al. (2011) (11 sets total); Bouhemadou et al. (2015) (six sets total, $\mathrm{SiZn}_{2} \mathrm{O}_{4}$ and $\mathrm{SiCd}_{2} \mathrm{O}_{4}$ ); Fortes (2015) (two sets total); Bindi et al. (2018); Sousa et al. (2018) (four sets total); Cámara et al. (2019) (two sets total).

Although more data could be added to the present set (e.g. Princivalle et al., 2006, 2012; Lenaz et al., 2009, 2011, 2014, 2015; Bosi et al., 2016; Bosi \& Andreozzi, 2017; Fregola et al., 2012), they were not included due to overlap with the previous data. As the value of the $u$ parameter depends on the choice of unit-cell origin, the data of the present study that were not referred to, which have an origin of a cubic cell at the centre of symmetry $\overline{3} m$ [(Wyckoff position at $16 a$ corresponding to the fractional coordinates $(0,0,0)]$, have been converted accordingly.

\section{Chemical flexibility and structural tolerance of spinel}

The chemical flexibility of oxide spinels is extraordinarily variable. Table 1 shows the occurrence of at least 36 constituents with different formal charges/sizes that have been identified in natural and synthetic spinels.

It is interesting to note that the spinel structure accommodates this large number of constituents despite having the very simple structural formula type $T M_{2} \mathrm{O}_{4}$. The much more complex tourmaline, $X Y_{3} Z_{6}\left(T_{6} \mathrm{O}_{18}\right)\left(\mathrm{BO}_{3}\right)_{3} V_{3} W$, accommodates only about 26 (e.g. Bosi, 2018). An example showing the high structural tolerance of spinel is given by the comparison with the more complicated structure of feldspar: for example, anorthite $\mathrm{CaAl}_{2} \mathrm{Si}_{2} \mathrm{O}_{8}$ does not have an $\mathrm{Mg}$ analogue. The feldspar structure cannot accommodate smaller cations such as $\mathrm{Mg}$ due to the large difference in size between the crystal radii (Shannon, 1976) of ${ }^{[8]} \mathrm{Ca}^{2+}(1.26 \AA)$ and 
${ }^{[8]} \mathrm{Mg}^{2+}(1.03 \AA)$, which is $0.23 \AA$. On the other hand, there exists $\mathrm{HgCr}_{2} \mathrm{O}_{4}$ and its $\mathrm{Mg}$ analogue $\mathrm{MgCr}_{2} \mathrm{O}_{4}$; the spinel structure can accommodate $\mathrm{Mg}$ by moving $\mathrm{O}$ atoms along [111], despite the large difference in the crystal radii between ${ }^{\left[{ }^{[4]}\right.} \mathrm{Hg}^{2+}(1.10 \AA)$ and ${ }^{[4]} \mathrm{Mg}^{2+}(0.71 \AA)$ of $0.39 \AA$. Note, in the present study the crystal radii are preferred to the traditional ionic radius as the former corresponds more closely to the physical size of ions in a solid (Shannon, 1976).

Although the spinel structure might seem to be rigid because only two variable parameters ( $u$ and $a$ ) are necessary to define all the other geometrical parameters, the wide compositional range of spinel shows that it has a remarkable degree of tolerance; the oxygen array can easily expand (or contract) around the crystallographic $T$ and $M$ sites to accommodate cations of different charge and size.

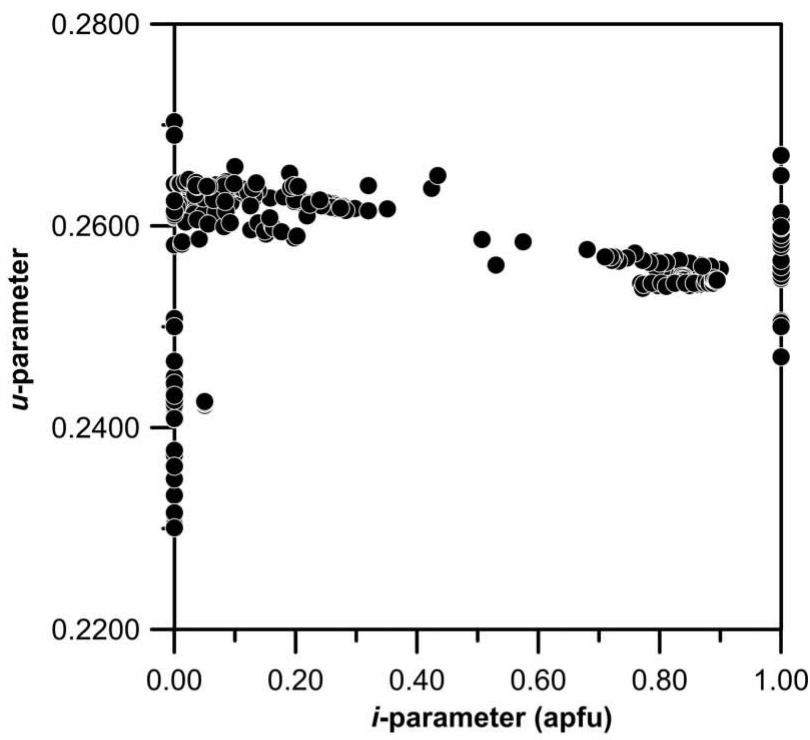

(a)

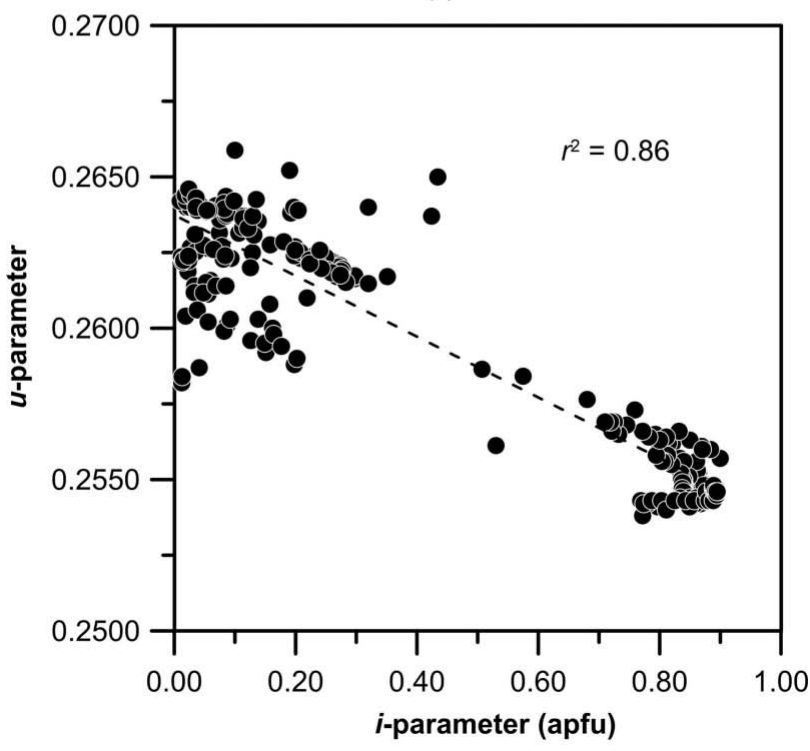

(b)

Figure 1

(a) Plot of $u$ versus $i$ for all data sets (349). (b) Similar plot for spinels with $u>0.25$ and $0<i<1$ (253 data sets). Dashed line is the linear fit.

\section{Inversion parameter}

The main factors that affect the $i$ parameter may be either an external origin, such as equilibrium temperature, oxygen fugacity and crystal growth kinetics, or internal, such as crystal-field stabilization energy, the electrostatic contribution to the lattice energy, covalence effects, size and charge (O'Neill \& Navrotsky, 1984; Nell et al., 1989; O'Neill et al., 1992; Della Giusta et al., 1996; Redfern et al., 1999; Sickafus et al., 1999; Andreozzi et al., 2000; Andreozzi \& Princivalle, 2002; Papike et al., 2015; Bosi \& Andreozzi, 2017). In general, one would expect a compositional dependence for the relation between $i$ and $u$. Instead, data for 349 spinel oxides show a limited correlation between $i$ and $u$ [Fig. 1(a)]. However, when the data are restricted to spinels with $u>0.25$ and $0<i<1(253$ data sets), a good negative correlation involving 2-3 spinels only is found [Fig. 1(b)].

\section{Distortion of the spinel structure}

The $u$ parameter may be used as a measure of the distortion of the spinel structure from ideal close-packing $(u=0.25)$ or of the angular distortion of the octahedron (Bosi et al., 2010). Theoretically, the $u$ parameter varies from 0.226 to 0.274 (Hill et al., 1979). Empirically, $u$ varies from 0.2301 and 0.2703 (Weil \& Stöger, 2006; Sousa et al., 2018): for $u<0.25$, the $M \mathrm{O}_{6}$ octahedron is flattened along the threefold axis along [111], whereas for $u>0.25$, it is elongated. With regards to the angular distortion of $M \mathrm{O}_{6}$, Fig. 2 shows the strict relations between the bond-angular variance (Robinson et al., 1971) and the $u$ parameter. Consequently, the distortion of the spinel structure can also be explained in terms of angular distortion of the octahedra.

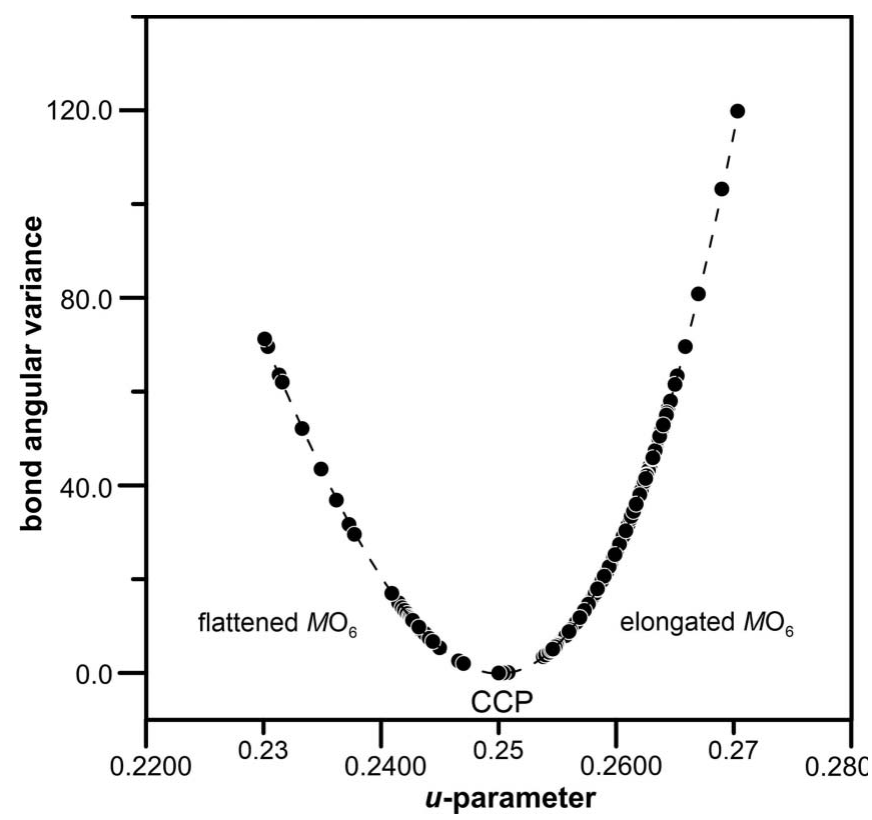

Figure 2

Plot of the bond-angular variance versus $u$, illustrating their strict relationship. Dashed line is the cubic fit $\left(r^{2}=0.99998\right)$ and c.c.p. $(u=0.25)$ corresponds to a regular octahedron: bond angles $=90^{\circ}$ and equal edges. 
For symmetry reasons, the anion is displaced along the $\langle 111\rangle$ directions, resulting in variation of the $u$ parameter: an increase in $u$ produces larger $T-\mathrm{O}$ and smaller $M-\mathrm{O}$ distances and vice versa. As $T-\mathrm{O}$ and $M-\mathrm{O}$ are related to $u$ and $a$, we can consider the first derivative of these relations with respect to $u$ :

$$
\begin{gathered}
T-\mathrm{O}=\sqrt{3}\left(u-\frac{1}{8}\right) a, \\
\frac{\partial(T-\mathrm{O})}{\partial u}=+\sqrt{3} a=+1.73 a
\end{gathered}
$$

and

$$
M-\mathrm{O}=\left(3 u^{2}-2 u+\frac{3}{8}\right)^{1 / 2} a
$$

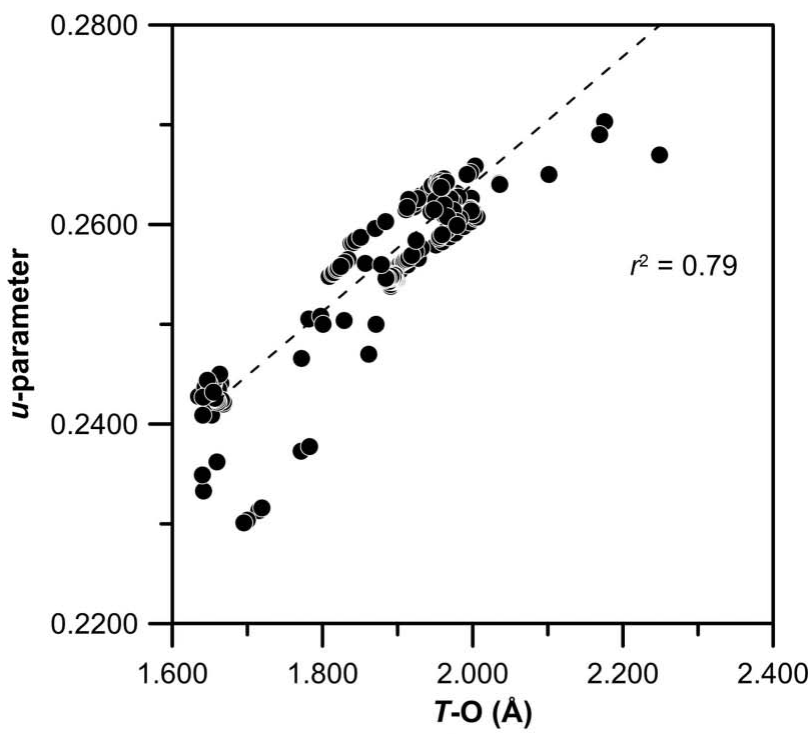

(a)

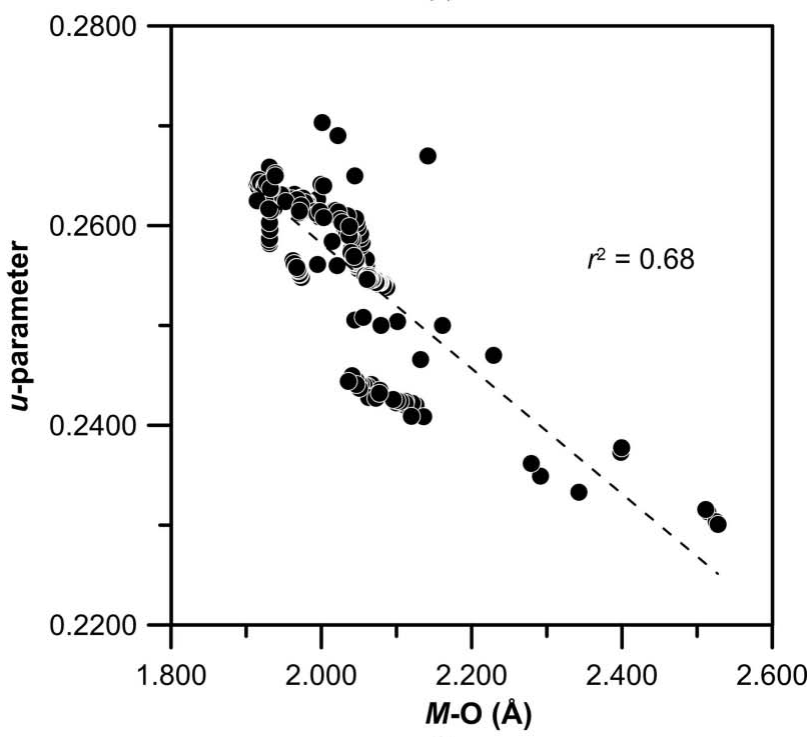

(b)

Figure 3

Relationships between the $u$ parameter and $(a)$ the tetrahedral $(T-\mathrm{O})$ and $(b)$ octahedral $(M-\mathrm{O})$ bond distances in $F d \overline{3} m$ spinel oxides. Dashed lines are the linear fits.

$$
\frac{\partial(M-\mathrm{O})}{\partial u}=\frac{3 u-1}{\left(3 u^{2}-2 u+\frac{3}{8}\right)^{1 / 2}} a=-k a .
$$

For values of $u$ ranging from 0.226 to $0.274,-1.17<k<-0.78$. These results indicate that any infinitesimal change in $T-\mathrm{O}$ is directly proportional to $u$ by the coefficient of proportionality $+1.73 a$, and that any infinitesimal change in $M-\mathrm{O}$ is inversely proportional to $u$ by the coefficient of proportionality $-k a$. Moreover, the variation in $T-\mathrm{O}$ is larger than that in $M-\mathrm{O}$.

Data from the literature confirm these theoretical trends, showing a positive correlation between $u$ and $T-\mathrm{O}$ and a negative correlation between $u$ and $M-\mathrm{O}$ (Fig. 3). Moreover, there is a negative correlation between $u$ and the mean formal charge at $T$, whereas a positive correlation is found between $u$ and the mean formal charge at $M$ (Fig. 4). As a result, size and

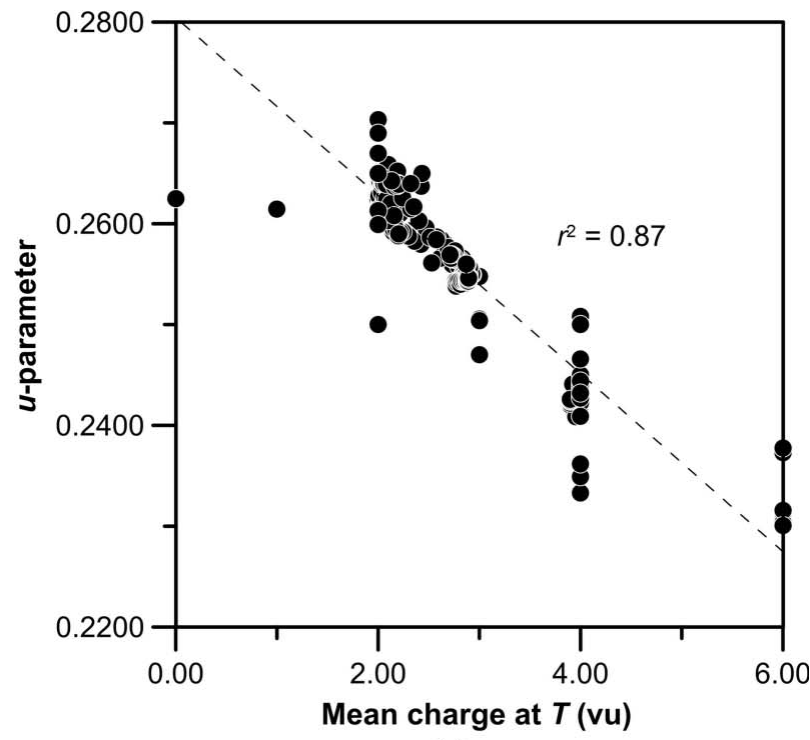

(a)

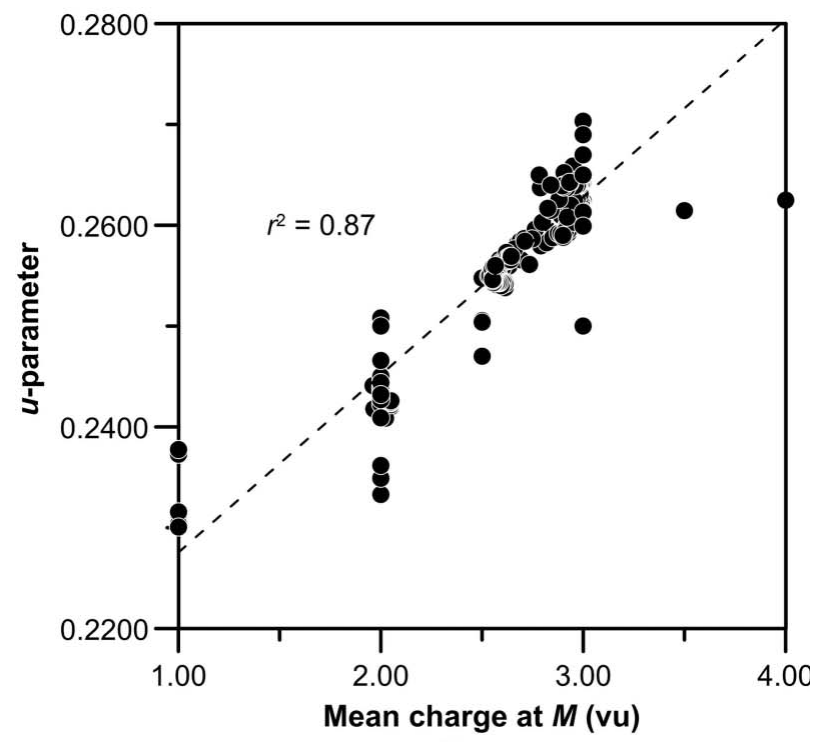

(b)

Figure 4

Relationships between $u$ and $(a)$ the mean charge at the $T$ site and $(b)$ the mean formal charge at the $M$ site in $F d \overline{3} m$ spinel oxides. Dashed lines are the linear fits. 
charge of ions seem to play an important role in determining structural distortion in the spinel oxides. However, a significant variation in $u$ for any given value of formal charge can be noted, e.g. for $T$ charge $=+4$ or $M$ charge $=+2, u$ varies from $\sim 0.23$ to $\sim 0.25$. This type of variation may be explained by the ionic potential (IP), which merges the charge and size features of an ion: IP = charge/size. The latter may be calculated as the ratio of the mean formal charge of the cations occupying the $T$ and $M$ sites to the mean cation size at $T$ and $M$ obtained from $T-\mathrm{O}$ and $M-\mathrm{O}$ distances minus the oxygen crystal radius: ${ }^{[4]} \mathrm{O}^{2-}=1.24 \AA$, respectively (Shannon, 1976). Both IP at $T$ and $M$ show a very good correlation with the $u$ parameter: ${ }^{T} \mathrm{IP}$ and ${ }^{M}$ IP have a negative and a positive relationship with $u$, respectively (Fig. 5).

In accordance with the stabilizing feature that Pauling (1929) ascribed to cation-cation Coulomb terms (Pauling's

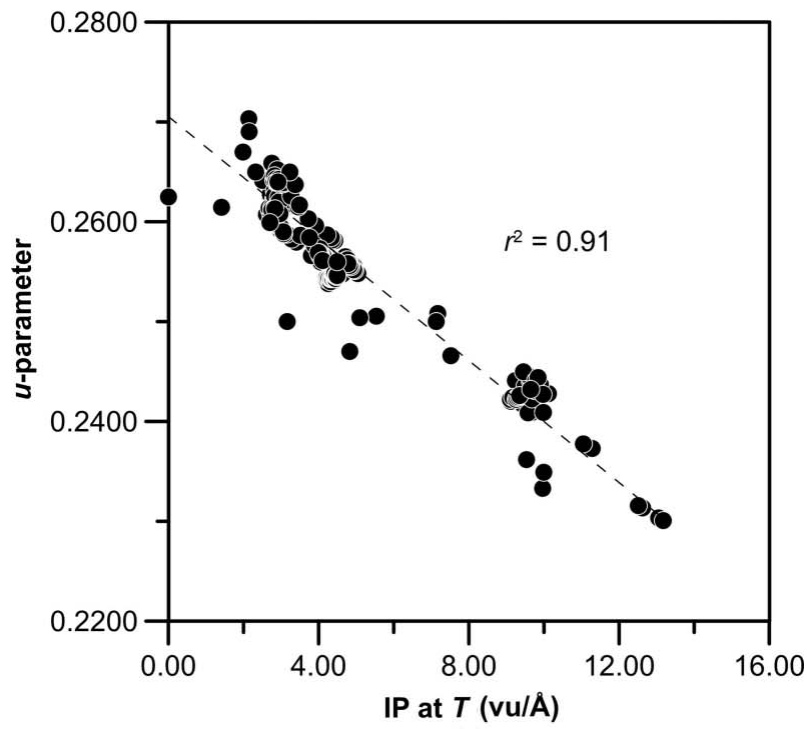

(a)

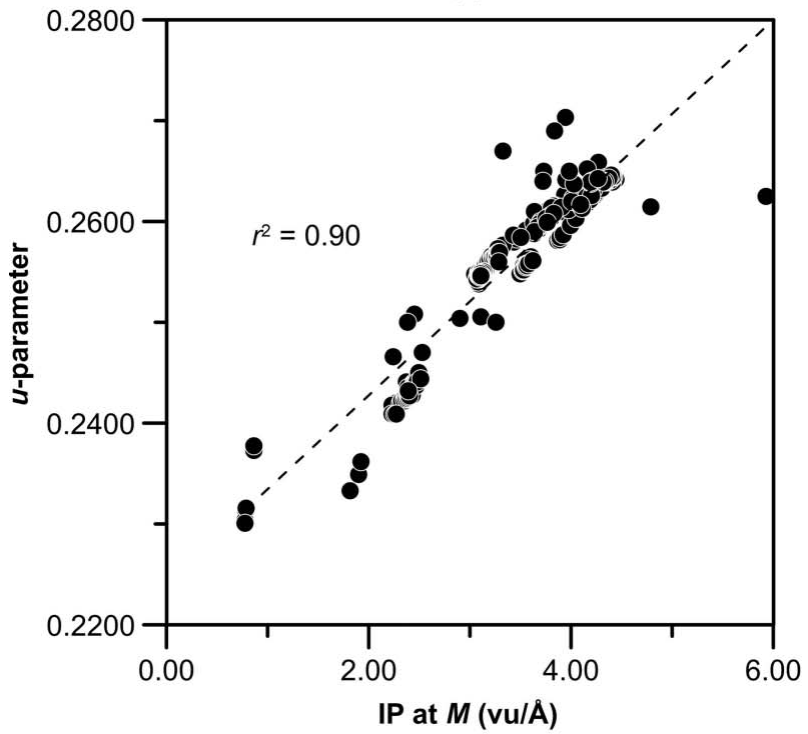

(b)

Figure 5

Relationships between $u$ and (a) IP at the $T$ site and (b) IP at the $M$ site in $F d \overline{3} m$ spinel oxides. Dashed lines are the linear fits. third rule), the effect of ${ }^{T}$ IP on $u$ may be related to cationcation repulsion at $T$ across the triangular faces of the tetrahedra (Fig. 6). Moreover, the observation of a negative correlation between ${ }^{T} \mathrm{IP}$ and the area of the face of the tetrahedron is consistent with ions with the highest ${ }^{T} \mathrm{IP}$ values, inducing a reduction of the face or edge ${ }^{T}(\mathrm{O}-\mathrm{O})$ of the tetrahedron in order to increase oxygen shielding of cation repulsion. A similar mechanism explains the negative correlation between ${ }^{M} \mathrm{IP}$ and ${ }^{M}(\mathrm{O}-\mathrm{O})_{\mathrm{sh}}$ distances (Fig. 7), i.e. ${ }^{M} \mathrm{IP}$

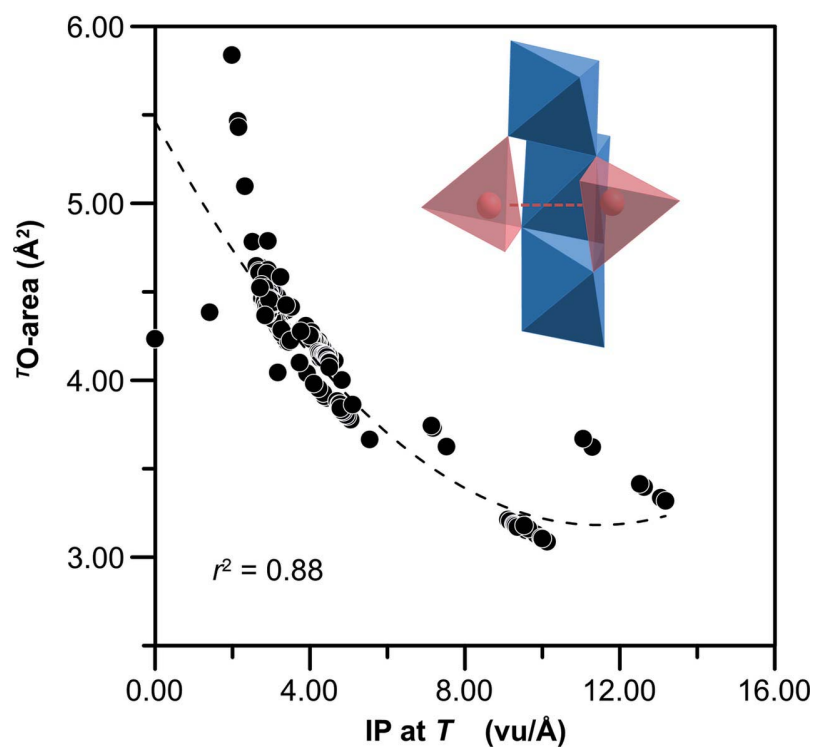

Figure 6

The negative correlation between ${ }^{T} \mathrm{IP}$ and the triangular face area $\left({ }^{T} \mathrm{O}\right.$ area) indicates that ions with the highest ${ }^{T} \mathrm{IP}$ values induce edge shorting of $\mathrm{TO}_{4}$ (i.e. a reduction in the area of the face of the tetrahedron) to increase the oxygen shielding effect of the $T-T$ repulsion. Dashed line is the quadratic fit.

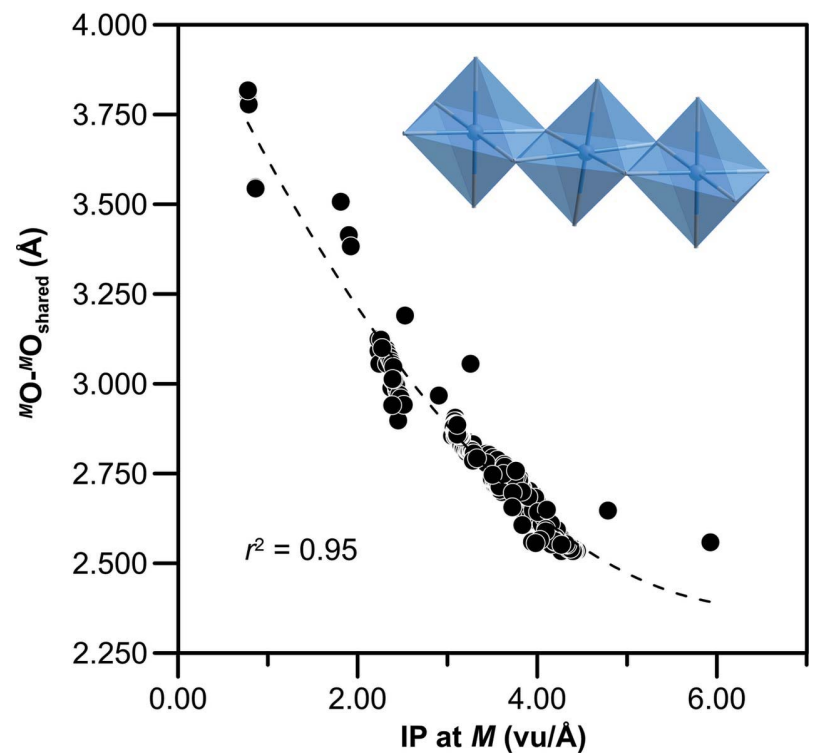

Figure 7

Negative correlation between ${ }^{M} \mathrm{IP}$ and ${ }^{M} \mathrm{O}-{ }^{M} \mathrm{O}$. As ${ }^{M} \mathrm{IP}$ is proportional to the charge density at $M$, an increase in ${ }^{M}$ IP leads to a decrease in ${ }^{M}(\mathrm{O}-\mathrm{O})_{\text {shared }}$, which provides a proportional oxygen shielding effect to the $M-M$ repulsion. Dashed line is the quadratic fit. 
is linked to cation-cation repulsion across the shared edges, ${ }^{M}(\mathrm{O}-\mathrm{O})_{\text {sh }}$, of the octahedral network at the $M$ sites. The fact that the $M-M$ distance $(2.82-3.29 \AA)$ is much shorter than the $T-T$ distance (3.45-4.03 $\AA$ ) suggests that the $M-M$ interaction is stronger than that of $T-T$.

Finally, it should be noted that the ${ }^{M}(\mathrm{O}-\mathrm{O})_{\mathrm{sh}}$ distances are always larger than $2.50 \AA$ in the present data set (Fig. 7). Moreover, ${ }^{M}(\mathrm{O}-\mathrm{O})_{\text {sh }}$ decreases with as $u$ increases and vice versa (Fig. 8). In general, the $\mathrm{O}$ atoms move along [111] as a function of both size and charge of ions in such a way that some $\mathrm{O}-\mathrm{O}$ distances become shorter (and others longer) with

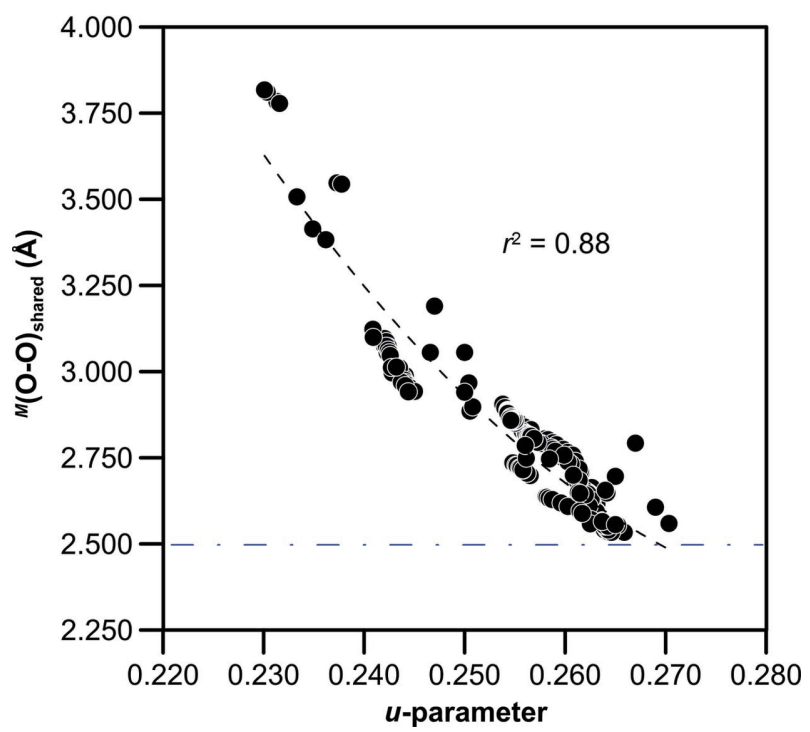

Figure 8

Variation of $u$ with ${ }^{M}(\mathrm{O}-\mathrm{O})_{\text {shared. }}$. Dash dotted (blue) line represents the empirical lower limit where the $\mathrm{O}$ atoms cannot be pushed closer together. Dashed line is the quadratic fit.

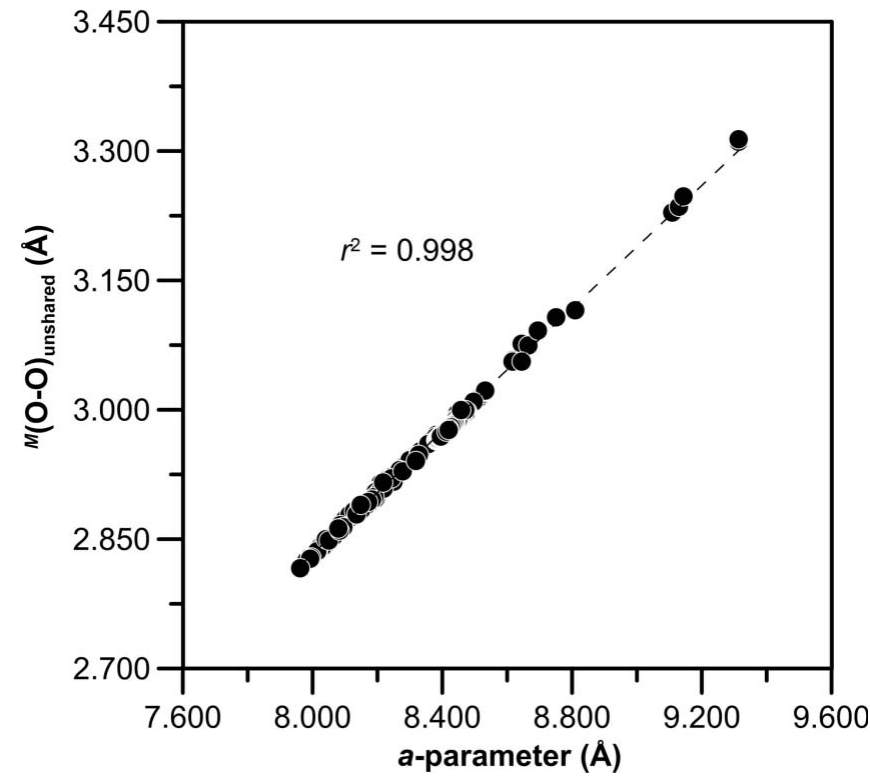

Figure 9

Variation of the unshared octahedral edge ${ }^{M}(\mathrm{O}-\mathrm{O})_{\text {unshared }}$ with $a$, showing the excellent correlation between these parameters according to the regression model: ${ }^{M}(\mathrm{O}-\mathrm{O})_{\text {unshared }}=0.356 a+0.015$. Dashed line is the linear fit. respect to the ideal oxygen close packing. The empirical lower limit, where the $\mathrm{O}$ atoms cannot be pushed closer together, corresponds to ${ }^{M}(\mathrm{O}-\mathrm{O})_{\text {sh-min }} \simeq 2.50 \AA$ (Fig. 8), which is consistent with the theoretical prediction of Hill et al. (1979): shared edges between spinel oxide octahedra will not, in general, fall below $2.4 \AA$ because of rapidly increasing nonbonding repulsion forces. The unshared octahedral edge ${ }^{M}(\mathrm{O}-\mathrm{O})_{\text {unsh }}$ shows no correlation with $u$ but a highly positive correlation with the $a$ parameter (Fig. 9). No general correlation was observed for $a$ versus $u$ as well as for T-O versus $M-\mathrm{O}$.

\section{Conclusions}

The spinel structure can be defined as rigid because only two variables ( $u$ and $a$ ) are necessary to describe its geometry, but the interplay between tetrahedra and octahedra allows remarkable spinel chemical flexibility. The site-charge variations are larger at $T$ (from 0 to +6$)$ than at $M($ from +1 to +4$)$ because of the ratio of $T$ to $M$ sites, which must be equal to 1:2, in accordance with the stoichiometry of the spinel structure: ${ }^{T}\left(A_{1-i} B_{i}\right)^{M}\left(A_{i} B_{2-i}\right) \mathrm{O}_{4}$. The structure of the spinel oxides is able to tolerate many constituents (at least 36 ) by expansion or contraction of the tetrahedra and octahedra. This is reflected in the large variation in $T-\mathrm{O}(1.64-2.25 \AA)$ and $M-\mathrm{O}(1.91-$ $2.53 \AA)$ as well as in $u(0.23-0.27)$. The latter varies with respect to the ideal c.c.p. $(u=0.25)$, giving a bond angular distortion of the octahedron and hence of the whole spinel structure. With respect to $u=0.2625$ (at which, $T-\mathrm{O}=M-$ O), $T-\mathrm{O}$ may be $\sim 0.20 \AA$ larger than $M-\mathrm{O}$, whereas $M-\mathrm{O}$ may be about $\sim 0.70 \AA$ larger than $T-\mathrm{O}$. In general, distortion of the spinel structure can be best explained in terms of variation in IP, which merges the steric and electronic properties of an ion: sterically induced distortion is obviously dependent on ion size, whereas electrostatically induced distortion is caused by cation-cation repulsion across faces of tetrahedra and shared edges of octahedra. About $90 \%$ of the observed structure distortion can be described by linear regression models between $u$ and either ${ }^{T}$ IP or ${ }^{M}$ IP. Values of $u$ $\gg 0.27$ result in ${ }^{M}(\mathrm{O}-\mathrm{O})$ distances shorter than $2.50 \AA$, which would lead to structural instability because of increased nonbonded repulsion between the oxygen atoms.

\section{References}

Andreozzi, G. B. \& Princivalle, F. (2002). Am. Mineral. 87, 838-844. Andreozzi, G. B., Princivalle, F., Skogby, H. \& Della Giusta, A. (2000). Am. Mineral. 85, 1164-1171.

Antao, S. M., Hassan, I. \& Parise, J. B. (2005). Am. Mineral. 90, 219 228.

Bindi, L., Griffin, W. L., Panero, W. R., Sirotkina, E., Bobrov, A. \& Irifune, T. (2018). Sci. Rep. 8, 5457.

Bosi, F. (2018). Am. Mineral. 103, 298-306.

Bosi, F. \& Andreozzi, G. B. (2017). Am. Mineral. 102, 333-340.

Bosi, F., Andreozzi, G. B., Ferrini, V. \& Lucchesi, S. (2004). Am. Mineral. 89, 1367-1373.

Bosi, F., Hålenius, U., Andreozzi, G. B., Skogby, H. \& Lucchesi, S. (2007). Am. Mineral. 92, 27-33.

Bosi, F., Hålenius, U. \& Skogby, H. (2009). Am. Mineral. 94, 181-189. Bosi, F., Hålenius, U. \& Skogby, H. (2010). Am. Mineral. 95, 602-607. 
Bosi, F., Skogby, H., Fregola, R. A. \& Hålenius, U. (2016). Am. Mineral. 101, 580-586.

Bouhemadou, A., Allali, D., Bin-Omran, S., Abud Al Safi, E. M., Khenata, R. \& Al-Douri, Y. (2015). Mater. Sci. Semicond. Process. 38, 192-202.

Cámara, F., Bindi, L., Pagano, A., Pagano, R., Gain, S. E. M. \& Griffin, W. L. (2019). Minerals, 9, 4.

Carbonin, S., Russo, U. \& Della Giusta, A. (1996). Mineral. Mag. 60, 355-368.

Casado, P. G. \& Rasines, I. (1982). Z. Kristallogr. 160, 33-37.

Della Giusta, A., Carbonin, S. \& Ottonello, G. (1996). Mineral. Mag. 60, 603-616.

Della Giusta, A., Princivalle, F. \& Carbonin, S. (1986). N. Jahrb. Mineral. Abh. 155, 319-330.

Díez Viñuela, J. S., Areán, C. O. \& Stone, F. S. (1983). J. Chem. Soc. Faraday Trans. 1, 79, 1191-1198.

Finger, L. W., Hazen, R. M. \& Yagi, T. (1979). Am. Mineral. 64, 1002 1009.

Fortes, A. D. (2015). Acta Cryst. E71, 592-596.

Fregola, R. A., Bosi, F., Skogby, S. \& Hålenius, U. (2012). Am. Mineral. 97, 1821-1827.

Furuhashi, H., Inagaki, M. \& Naka, S. (1973). J. Inorg. Nucl. Chem. 35, 3009-3014.

Greedan, J. E., Raju, N. P., Wills, A. S., Morin, C., Shaw, S. M. \& Reimers, J. N. (1998). Chem. Mater. 10, 3058-3067.

Hålenius, U., Bosi, F. \& Skogby, H. (2007). Am. Mineral. 92, 12251231.

Hazen, R. M., Downs, R. T., Finger, L. W. \& Jaidong Ko, K. (1993). Am. Mineral. 78, 1320-1323.

Hill, R. J., Craig, J. R. \& Gibbs, G. V. (1979). Phys. Chem. Miner. 4, 317-339.

Iida, S. (1957). J. Phys. Soc. Jpn, 12, 222-233.

Kudoh, Y., Kuribayashi, T., Mizobata, H., Ohtani, E., Sasaki, S. \& Tanaka, M. (2007). J. Mineral. Petrol. Sci. 102, 8-11.

Larsson, L., O'Neill, H. St C. \& Annersten, H. (1994). Eur. J. Mineral. 6, 39-52.

Lavina, B., Koneva, A. \& Della Giusta, A. (2003b). Eur. J. Mineral. 15, 435-441.

Lavina, B., Reznitskii, L. \& Bosi, F. (2003a). Phys. Chem. Miner. 30, 599-605.

Lenaz, D., Logvinova, A. M., Princivalle, F. \& Sobolev, N. V. (2009). Am. Mineral. 94, 1067-1070.

Lenaz, D., O’Driscoll, B. \& Princivalle, F. (2011). Contrib. Mineral. Petrol. 162, 1201-1213.

Lenaz, D., Princivalle, F. \& Schmitz, B. (2015). Mineral. Mag. 79, 755765.

Lenaz, D., Skogby, H., Princivalle, F. \& Hålenius, U. (2004). Phys. Chem. Miner. 31, 633-642.

Lenaz, D., Youbi, N., De Min, A., Boumehdi, M. A. \& Ben Abbou, M. (2014). Am. Mineral. 99, 267-275.

Lucchesi, S., Amoriello, M. \& Giusta, A. D. (1998a). Eur. J. Mineral. 10, 473-482.

Lucchesi, S., Bosi, F. \& Pozzuoli, A. (2010). Am. Mineral. 95, 617-621.

Lucchesi, S. \& Della Giusta, A. (1994). Z. Kristallogr. 209, 714-719.

Lucchesi, S. \& Della Giusta, A. (1997). Mineral. Petrol. 59, 91-99.

Lucchesi, S., Della Giusta, A. \& Russo, U. (1998b). Mineral. Mag. 62, 41-54.

Lucchesi, S., Russo, U. \& Della Giusta, A. (1997). Eur. J. Mineral. 9, 31-42.

Lucchesi, S., Russo, U. \& Giusta, A. D. (1999). Eur. J. Mineral. 11, 501-512.
Marumo, F., Isobe, M. \& Akimoto, S. (1977). Acta Cryst. B33, 713716.

Matsuno, K., Katsufuji, T., Mori, S., Moritomo, Y., Machida, A., Nishibori, E., Takata, M., Sakata, M., Yamamoto, N. \& Takagi, H. (2001). J. Phys. Soc. Jpn, 70, 1456-1459.

Matsushita, Y., Yamaura, J.-I. \& Ueda, Y. (2005). Acta Cryst. E61, i137-i139.

Millard, R. L., Peterson, R. C. \& Hunter, B. K. (1995). Am. Mineral. 80, 885-896.

Nakatsuka, A., Ikeda, Y., Nakayama, N. \& Mizota, T. (2006). Acta Cryst. E62, i109-i111.

Nell, J., Wood, B. J. \& Mason, T. O. (1989). Am. Mineral. 74, 339-351.

Nestola, F., Balić-Žunić, T., Koch-Müller, M., Secco, L., Princivalle, F., Parisi, F. \& Dal Negro, A. (2011). Mineral. Mag. 75, 2649-2655.

O'Neill, H. St C. (1992). Eur. J. Mineral. 4, 571-580.

O'Neill, H. St C., Annersten, H. \& Virgo, D. (1992). Am. Mineral. 77, $725-740$.

O’Neill, H. St C. \& Dollase, W. A. (1994). Phys. Chem. Miner. 20, 541-555.

O’Neill, H. St C., Dollase, W. A. \& Ross, C. R. II (1991). Phys. Chem. Miner. 18, 302-319.

O’Neill, H. St C. \& Navrotsky, A. (1984). Am. Mineral. 69, 733-753.

Papike, J. J., Burger, P. V., Bell, A. S., Shearer, C. K., Le, L. \& Jones, J. (2015). Am. Mineral. 100, 2018-2025.

Pauling, L. J. (1929). J. Am. Chem. Soc. 51, 1010-1026.

Peterson, R. C., Lager, G. A. \& Hitterman, R. L. (1991). Am. Mineral. 76, 1455-1458.

Princivalle, F., Martignago, F. \& Dal Negro, A. (2006). Am. Mineral. 91, 313-318.

Princivalle, F., Della Giusta, A., De Min, A. \& Piccirillo, E. M. (1999). Miner. Mag. 63, 257-262.

Princivalle, F., Martignago, F., Nestola, F. \& Negro, A. D. (2012). Eur. J. Mineral. 24, 633-643.

Redfern, S. A. T., Harrison, R. J., O’Neill, H. St C. \& Wood, D. R. R. (1999). Am. Mineral. 84, 299-310.

Reuter, B., Riedel, E., Hug, P., Arndt, D., Geisler, U. \& Behnke, J. (1969). Z. Anorg. Allg. Chem. 369, 306-312.

Robinson, K., Gibbs, G. V. \& Ribbe, P. H. (1971). Science, 172, $567-$ 570.

Roelofsen, J. N., Peterson, R. C. \& Raudsepp, M. (1992). Am. Mineral. 77, 522-528.

Rohrer, G. S. (2001). Structure and Bonding in Crystalline Materials, pp. 548. Cambridge University Press.

Shannon, R. D. (1976). Acta Cryst. A32, 751-767.

Sickafus, K. E., Wills, J. M. \& Grimes, N. W. (1999). Struct. Spinel. J. Am. Ceram. Soc. 82, 3279-3292.

Siegel, L. A. (1978). J. Appl. Cryst. 11, 284-286.

Sousa, G. D. S., Nobre, F. X., Araújo Júnior, E. A., Sambrano, J. R., Albuquerque, A. D. R., Bindá, R. D. S., Couceiro, P. R. D. C., Brito, W. R., Cavalcante, L. S., Santos, M. R. D. M. C. \& de Matos, J. M. E. (2018). Arab. J. Chem. In the press, doi: 10.1016/ j.arabjc.2018.07.011.

Von Dreele, R. B., Navrotsky, A. \& Bowman, A. L. (1977). Acta Cryst. B33, 2287-2288.

Waerenborgh, J. C., Figueiredo, M. O., Cabral, J. M. P. \& Pereira, L. C. J. (1994a). Phys. Chem. Miner. 21, 460-468.

Waerenborgh, J. C., Figueiredo, M. O., Cabral, J. M. P. \& Pereira, L. C. J. (1994b). J. Solid State Chem. 111, 300-309.

Weil, M. \& Stöger, B. (2006). Acta Cryst. E62, i199-i200.

Welch, M. D., Cooper, M. A. \& Hawthorne, F. C. (2001). Mineral. Mag. 65, 441-444. 